\title{
FGFR2 Mutation Analysis
}

National Cancer Institute

\section{Source}

National Cancer Institute. FGFR2 Mutation Analysis. NCI Thesaurus. Code C157180.

A procedure used to detect and identify mutations in the FGFR2 gene. 